\title{
Microalbuminuria and coronary heart disease in non-diabetics
}

\section{Donal Buggy, John Feely, John Murphy' ${ }^{1}$, Cathal O’Sullivan² and Michael Walsh $^{2}$}

\author{
Department of Pharmacology and Therapeutics, Trinity College Medical School, ${ }^{1}$ Department of \\ Radiology and ${ }^{2}$ Department of Cardiology, St James's Hospital, Dublin 8, Ireland
}

\begin{abstract}
Summary: Microalbuminuria (or urinary albumin excretion rates (AER) above normal limits) is associated with coronary heart disease (CHD) particularly in diabetics. To determine the sensitivity and specificity of AER for CHD in a non-diabetic population we prospectively studied 115 consecutive patients undergoing coronary angiography and 66 undergoing exercise electrocardiography (ECG). There was no relationship between AER and the severity of CHD determined by angiography (Gensini-scored). While microalbuminuria (AER $>20 \mu \mathrm{g} /$ minute) was $91 \%$ specific it had low sensitivity (12\%). Microalbuminuria is not a sensitive indicator of CHD in a non-diabetic population.
\end{abstract}

\section{Introduction}

Increasing evidence suggests that microalbuminuria excretion of abnormal levels of urinary albumin, undetectable by reagent strips, usually expressed as albumin excretion rate (AER) is of pathological significance. It is strongly prognostic of renal failure, proliferative retinopathy and cardiovascular mortality in patients with insulindependent and non-insulin-dependent (NIDDM) diabetes mellitus. ${ }^{1-7}$ Recently, an association between microalbuminuria and all causes of mortality in non-diabetic subjects has also been demonstrated. ${ }^{8,9}$ In the Islington Diabetes Survey, Yudkin et al. ${ }^{10}$ reported that microalbuminuria was a predictor of coronary heart disease (CHD) in non-diabetic subjects.

This study was undertaken to examine the strength of the suggested association between microalbuminuria and CHD in a cross-section of non-diabetic patients with angiographically or exercise electrocardiographically proven CHD, particularly to determine if it is predictive of the severity of coronary ischaemia.

\section{Subjects and methods}

A timed overnight urine collection was obtained from 115 consecutive, non-diabetic (normal fasting glucose) patients (age $57 \pm 10$ years, 95 male), undergoing coronary angiography. A midstream

Correspondence: Professor John Feely, M.D.

Accepted: 14 April 1993 urine was examined to exclude urinary tract infection as a cause of microalbuminuria. Time of bladder voiding before retiring was noted. AlB nocturia and first-morning urine was collectedTotal volume and collection time were noted.

Samples were Dipstix-tested (Ames Division, Miles Lab.) to rule out gross proteinuria and haematuria, and 61 were randomly neutralized to $\mathrm{pH}=7$ before being frozen at $-18^{\circ} \mathrm{C}$. They were assayed within 4 months using an immunoturbidimetric assay, ${ }^{11-13}$ coefficient of variation $(\mathrm{CV})=3.5 \%$ and $6.3 \%$ at $5 \mathrm{mg} / 1$ and $80 \mathrm{mg} / 1$, respectively. Forty-four random samples were also analysed by radioimmunoassay, ${ }^{14} \mathrm{CV}=2.7 \%$ and $3.9 \%$ at 5 and $80 \mathrm{mg} / 1$, respectively and there was a highly significant correlation $(r=0.98)$ between these two methods.

A distinct group of 63 consecutive patients (age $55 \pm 9.5$ years, mean \pm s.d., 43 males) gave random urine samples before and after exercise electrocardiogram (ECG). The bladder was emptied before exercise, and a modified Bruce Protocol used. No fluid was allowed prior to taking the post-exercise sample, as forced diuresis may interfere with true AER. ${ }^{15}$

Major cardiovascular risk factors were assessed on all patients. Hypertension was defined as blood pressure $\geqslant 150 / 90 \mathrm{mmHg}$. Fasting total cholesterol, blood glucose, past and current smoking history, family history of coronary heart disease and current drug therapies were noted. Cineangiography was analysed by a radiologist, blinded to the other results, according to the Gensini Score ${ }^{16}$ Resting ECG was analysed according to 
the Minnesota $\operatorname{Code}^{17}$ for evidence of coronary heart disease.

Logarithmic transformation was applied to AER values, which showed a positively skewed distribution. Multiple regression analysis was performed to study the independent influence of one variable on AER or Gensini Scores.

\section{Results}

Of the 115 patients undergoing angiography, 13 had microalbuminuria. There was no difference between AER values of neutralized and nonneutralized samples. Although the mean Gensini Score was 14.9 (range $0-84$ ), a score of four or more indicates $>75 \%$ occlusion of a major vessel and is taken to indicate significant coronary heart disease. The sensitivity of an AER value of $>20 \mu \mathrm{g} /$ minute for the presence of coronary heart disease (Gensini $>4$ ) was only $12 \%$ in this study. Specificity of AER of $<20 \mu \mathrm{g} /$ minute for the absence of CHD (Gensini <4) was $91 \%$. The positive predictive value of AER $>20 \mu \mathrm{g} /$ minute was $77 \%$. No association was found between AER and Gensini Scores (Spearman's rank correlation coefficient, $\rho=0.163, P>0.1)$. Neither did AER increase with more widespread vessel involvement.

Subjects with microalbuminuria (AER $>20 \mu \mathrm{g}$ / minute), were compared to those with normal levels $(n=102)$. These groups (Table I) were well matched for age, sex, current treatment regimens, body-mass index (BMI) and proportion of smokers. Serum creatinine levels were higher in the higher AER group but there was no association with CHD, blood pressure or cholesterol history nor family history of CHD.

Table I Comparison of patients with AER $>$ and $<20 \mu \mathrm{g} /$ minute $(x \pm$ s.d.)

\begin{tabular}{|c|c|c|c|}
\hline Variable & $\begin{array}{c}A E R> \\
20 \mu \mathrm{g} / \text { minute } \\
(\mathrm{n}=13)\end{array}$ & $\begin{array}{c}A E R< \\
20 \mu \mathrm{g} / \text { minute } \\
(\mathrm{n}=110)\end{array}$ & P value \\
\hline Age (years) & $61(7)$ & $57(10)$ & NS \\
\hline Sex (\% male) & $85 \%$ & $76 \%$ & NS \\
\hline Gensini Score & 17.04 & 14.78 & NS \\
\hline (+) Minnesota & $62 \%$ & $57 \%$ & NS \\
\hline Smokers & $77 \%$ & $74 \%$ & NS \\
\hline Hypertension & $46 \%$ & $24 \%$ & 0.08 \\
\hline $\begin{array}{l}\text { Cholesterol } \\
>6.2 \mathrm{mmol} / 1\end{array}$ & $31 \%$ & $39 \%$ & NS \\
\hline $\begin{array}{c}\text { Family history } \\
\text { of coronary } \\
\text { heart disease }\end{array}$ & $70 \%$ & $53 \%$ & NS \\
\hline $\begin{array}{l}\text { Serum creatinine } \\
(\mu \mathrm{mol} / \mathrm{l})\end{array}$ & $118.69(23.3)$ & $94.65(31.4)$ & 0.001 \\
\hline Body mass index & $25.88(2.0)$ & $25.21(3.0)$ & NS \\
\hline
\end{tabular}

NS $=$ not significant .
Comparing patients with coronary heart disease $(n=81)$ to those without $(n=34)$ these groups were well matched for age, BMI, blood pressure-cholesterol, smoking status and most drug groups (Table II). At an AER cut-off of $20 \mu \mathrm{g} /$ minute no difference was present between those with and without heart disease. Similarly the AER values were not different between these groups (Table II). As expected a much greater proportion of patients with CHD were male and had a family history of CHD. Patients with CHD were more likely to be on calcium antagonists but otherwise CHD was not significantly associated with other risk factors or drug groups. An ischaemic Minnesota Code was significantly associated with Gensini Scores $(P<0.05)$.

In patients undergoing exercise electrocardiography, a positive stress test (defined by onset of ST depression or T-wave inversion during or up to 5 minutes post-exercise, or the occurrence of chest pain relieved by sublingual nitrates) was obtained in 27 subjects. In 10 patients the urinary albumin was elevated $(>20 \mathrm{mg} / \mathrm{l})$ prior to exercise. There was a highly significant postexertional increase $(10.7 \pm 2.7$ to $70.5 \pm 9.5 \mathrm{mg} / 1, P<0.001)$ in the urinary excretion of albumin. The degree of increment expressed as the difference in creatininecorrected albumin concentration in post- and preexercise samples, was not related to positivity of the stress test or to the stage of Bruce Protocol at which the test was terminated.

Table II Comparison of patients with angiographically proven coronary heart disease (CHD) to those without (mean \pm s.d.)

\begin{tabular}{|c|c|c|c|}
\hline Variable & $\begin{array}{c}C H D \\
(\mathrm{n}=81)\end{array}$ & $\begin{array}{c}\text { Non-CHD } \\
(\mathrm{n}=34)\end{array}$ & $\mathrm{P}$ value \\
\hline $\begin{array}{l}\text { Age } \\
\text { (years) }\end{array}$ & $57.2(10.1)$ & $57.8(9.7)$ & NS \\
\hline$\%$ male & $84 \%$ & $64 \%$ & $<0.03$ \\
\hline Smoking & $77 \%$ & $67 \%$ & NS \\
\hline $\begin{array}{l}\text { Systolic BP } \\
(\mathrm{mmHg})\end{array}$ & $128.8(16.6)$ & $129(15.6)$ & NS \\
\hline $\begin{array}{l}\text { Diastolic BP } \\
\text { (mmHg) }\end{array}$ & $81.2(10.3)$ & 81.4 (11.9) & NS \\
\hline $\begin{array}{l}\text { AER } \\
(\mu \mathrm{g} / \text { minute })\end{array}$ & $12.9(24.3)$ & $11.0(24.9)$ & NS \\
\hline $\begin{array}{l}\text { Serum cholesterol } \\
(\mathrm{mmol} / \mathrm{l})\end{array}$ & $5.9(1.1)$ & $5.6(0.8)$ & NS \\
\hline $\begin{array}{l}\text { Family history } \\
\text { CHD }\end{array}$ & $65 \%$ & $32 \%$ & $<0.001$ \\
\hline $\begin{array}{l}\text { Serum creatinine } \\
(\mu \mathrm{mol} / \mathrm{l})\end{array}$ & $103.3(25.9)$ & $84.2(17.9)$ & $<0.001$ \\
\hline Body mass index & $25.4(2.8)$ & $24.7(2.6)$ & NS \\
\hline $\begin{array}{l}\text { Calcium } \\
\text { antagonist }\end{array}$ & $49 \%$ & $27 \%$ & $<0.05$ \\
\hline
\end{tabular}

NS = not significant $\mathbf{B P}=$ blood pressure 


\section{Discussion}

Microalbuminuria is now firmly established as a useful screening test to predict the development of nephropathy in diabetics. ${ }^{1-7}$ Recent population screening studies ${ }^{10,18}$ raised the possibility that microalbuminuria may be indicative of CHD. Our data in non-diabetic patients with angiographically or stress test-proven disease suggests that sensitivity and positive predictive value of AER for CHD are poor. Furthermore we did not find any relationship between AER and the severity of atheromatous lesions at angiography.

A number of factors may contribute to this discrepancy with the earlier studies of Yudkin et $a l .{ }^{10}$ and Damsgaard et al..$^{18}$ Firstly, the Islington Diabetes Survey may have recorded a spuriously high prevalence of CHD by using the WHO questionnaire to define CHD, relying in some cases on subjects' own history of angina or myocardial infarction, as chest pain frequently is falsely positive for CHD even if guided by WHO criteria. ${ }^{19}$ Secondly, subjects in the population screening study were not examined for asymptomatic urinary tract infection. Thirdly, subjects with CHD were significantly older than those deemed free of CHD. Subsequently, Damsgaard et $a .^{18}$ showed an association between AER and overall mortality in elderly non-diabetic subjects (aged 60-74 years). It is therefore possible that the association between AER and CHD reported by Yudkin et al. may in part reflect an age effect.

The Islington Diabetes Survey population was also significantly biased on the basis of selfselection as $45 \%$ of those with CHD had impaired glucose tolerance or frank diabetes, compared with $25 \%$ of the group without CHD. ${ }^{10}$ In addition, both systolic and diastolic blood pressure was significantly higher in those with CHD and as hypertension is associated with microalbuminuria ${ }^{20}$ this may also be contributory.

There is increasing evidence that patients with insulin resistance and hypertension are more likely to have microalbuminuria than those with normal glucose tolerance and systemic blood pressure. ${ }^{21,22} \frac{\varrho}{3}$ Glucose intolerance with hyperinsulinaemia may $\stackrel{\mathbb{Q}}{2}$ be a common denominator in the associated sub- $C$. group of patients with NIDDM, hyperlipidaemia, $\vec{F}$ hypertension and microalbuminuria. Since our population excluded patients with diabetes, the association of AER with coronary heart disease in $\frac{\bar{\sigma}}{\overline{5}}$ earlier studies may be explained in part through $\frac{\bar{\phi}}{\vec{\sigma}}$ diabetes and glucose intolerance.

We confirmed Damsgaard's association of AER के with serum creatinine noting a strong association $\vec{\circ}$ between CHD and serum creatinine. Damsgaard $\rightarrow$ also reported that creatinine predicted mortality $\vec{\omega}$ and that heart disease was the commonest cause..$^{18}$

There was a particularly strong association $\frac{6}{3}$ between family history of CHD and angiographic evidence of CHD. The strength of this association ${ }^{\circ}$ may be influenced by relatives themselves having $\stackrel{\infty}{-}$ risk factors for CHD such as excessive smoking, hypertension, hypercholesterolaemia, but we have $\partial$ not studied this.

Our exercise study confirms the postexertional 을 increment in microalbuminuria; $;^{15,23}$ however, no $\overrightarrow{C P}$ pattern between the level of increase and result of $\frac{\mathbb{}}{0}$ the exercise test was noted. Neither was exertional $\underset{\mathbb{D}}{\vec{D}}$ microalbuminuria related to the level of physical $\bar{\partial}$ activity achieved on the modified Bruce Protocol. H has been shown that angiotensin convertin $\vec{\theta}$ enzyme inhibitors reduce resting and exercise induced microalbuminuria. ${ }^{24,25}$ Perhaps individua differences in intraglomerular haemodynamics during exercise determines the degree of postexertional microalbuminuria which may be mediated by renal prostaglandins. ${ }^{26}$

In conclusion, we were unable to find an association between AER levels and established CHD. While there is evidence from other community studies that AER may be an indicator of overall mortality in older subjects over 60 years, this may reflect rising systolic blood pressure and glucose intolerance in the elderly. The value of AER as an independent specific marker of CHD in the younger non-diabetic patient population is not established.

\section{References}

1. Viberti, G.C., Hill, R., Jarrett, R., Argyropoulos, A., Mahmud, U. \& Keen, U. Microalbuminuria as a predictor of clinical nephropathy in insulin dependent diabetes mellitus. Lancet 1982, i: 1430-1432.

2. Mogensen, C.E. \& Christensen, C.K. Predicting diabetic nephropathy in insulin dependent patients. $N$ Engl J Med 1984, 311: 89-93.

3. Mogensen, C.E. Microalbuminuria predicts clinical proteinuria and early mortality in maturity onset diabetes. $N$ Engl J Med 1984, 310, 356-360.
4. Jarrett, R.J., Viberti, V.C., Argyropoulos, A., Hill, R.D., Mahmud, U. \& Murrels, T.J. Microalbuminuria predicts mortality in non insulin dependent diabetes. Diabetic Med 1984, 1: 17-19.

5. Mattock, M.B., Keen, H., Viberti, V.C. et al. Coronary heart disease and urinary albumin excretion rat in Type 2 (noninsulin-dependent) diabetic patients. Diabetologia 1988, 31: 82-87. 
6. Barnett, A.H., Dallinger, K., Jennings, R., Frekber, J. \& Odugbesan, $\mathrm{O}$. Microalbuminuria and diabetic retinopathy. Lancet 1985 , i: $53-54$.

7. Borch-Johnsen, K. \& Kriener, S. Proteinuria: a predictor of cardiovascular mortality in insulin dependent diabetes mellitus. Br Med J 1987, 294: 1651-1654.

8. Kannel, W.B., Stamper, M.J. \& Castelli, W.P. The prognostic significance of microalbuminuria. The Framingham Study. Am Heart J 1984, 108: 1347-1352.

9. Damsgaard, E., Froland, A. \& Mogensen, C.E. Microalbuminuria is a strong predictor of 6-year mortality in elderly Type 2 diabetics and non-diabetic subjects: a prospective study. Diabetologia 1988, 31: 483-484A.

10. Yudkin, J.S., Forrest, R.D. \& Jackson, C.A. Microalbuminuria as a predictor of vascular disease in non-diabetic subjects. Islington Diabetes Survey. Lancet 1988, ii: 530-532.

11. Elving, L.D., Bakkeren, J.A., Jansen, M.J. et al. Screening for microalbuminuria patients with diabetes: frozen storage of urine samples decreases their albumin content. Clin Chem 1989, 35: $308-310$.

12. Giampietro, O., Clerico, A., Cruschelli, L., Renno, G. \& Navalesi, R. Microalbuminuria and diabetes: more on urine storage and colorimetric assays. Clin Chem 1989, 35: $1560-1562$.

13. Spencer, K. \& Price, C.P. Kinetic immunoturbidity: the estimation of albumin. Clin Chim Acta 1979, 95: 263-276.

14. Keen, H. \& Chlouverakis, C. An immunoassay method for urinary albumin at low concentrations. Lancet 1963, ii: 913-916.

15. Gatling, W., Rowe, D. \& Hill, R.D. Microalbuminuria: an appraisal of assay techniques and urine collection procedures for measuring urinary albumin at low concentrations. Chap. 6. pp 41 - 49. In: Mogensen, E. (ed.) The Kidney and Hypertension in Diabetes Mellitus. Martinus Nijhoff Publishing, Boston, 1988.
16. Gensini, G.G. (ed.) Coronary Angiography, 2nd ed., 1985 Futura Publishing, New York.

17. Rose, G. \& Blackburn, H. Cardiovascular Survey Methods, WHO Monograph Series. WHO, Geneva, 1968, p. 56.

18. Damsgaard, E.M., Froland, A., Jorgensen, O.D. \& Mogensen, C.E. Microalbuminuria as predictor of increased mortality in elderly people. Br Med J 1990, 300: 297-300.

19. Braunwald, E. \& Isselbacher, J. (eds.) Harrison's Principles of Internal Medicine, 11 th ed. McGraw-Hill, New York, 1987.

20. Parving, H.H., Jensen, H. \& Mogensen, C.E. Increased urinary albumin excretion rate in benign essential hypertension. Lancet 1974, i: $1190-1193$.

21. Haffner, S.M., Stern, M.P., Gruber, M.K.K., Hazuda, H.P., Mitchell, B.D. \& Patterson, J.K. Microalbuminuria - potential for increased cardiovascular risk factors in non-diabetic subjects? Arteriosclerosis 1990, 10: 727-731.

22. Solini, A., Sambataro, M., Piarulli, F. et al. Type 2 diabetics with hypertension and microalbuminuria are more insulin resistant than normotensive type 2 diabetics. Diabetologia 1991, 34 (Suppl 2): A19.

23. Christian, C.K.\& Krussell, L.R. Acute and long term effect of antihypertensive treatment on exercise induced microalbuminuria. J Clin Hypertension 1987, 3: 704-712.

24. Marre, M., Chatellier, G., Leblanc, H., Guyene, T.T. Menard, J. \& Passa, P. Prevention of diabetic nephropathy with enalapril in normotensive diabetics with microalbuminuria. Br Med J 1988, 297: 1092-1095.

25. Romanelli, G., Giustina, A., Cimino, A. et al. Short term effect of captopril on microalbuminuria induced by exercise in normotensive diabetics. $\mathrm{Br} \mathrm{Med} J \mathrm{1}$ 1989, 298: 284-288.

26. Mathiesen, E.R., Hommel, E., Olsen, U.B. \& Parving, H.H. Elevated urinary prostaglandin excretion and the effect of indomethacin on renal function in incipient diabetic nephropathy. Diabetic Med 1988, 5: 145-149. 